\title{
El control judicial de la protección del patrimonio especialmente a través de la declaración de bienes de interés cultural: parámetros y jurisprudencia relevante
}

Maria del Amor Albert, letrada de la Junta de Andalucia, jefe del Área de Asuntos Contenciosos del Gabinete Jurídico

Comprender cómo funciona la dinámica del proceso judicial seguido ante nuestros tribunales cuando éstos revisan y controlan la actuación de las administraciones públicas, puede ser esencial para fortalecer su legalidad.

Nuestros tribunales controlan toda la actuación de la Administración Pública, como no puede ser de otro modo en un Estado de Derecho como el nuestro, y ese control es la garantía para el ciudadano de que la Administración, sujeta al principio de legalidad, sólo hace aquello que la ley le permite y en los términos y la forma en que la misma se lo permite.

El presente estudio pretende abordar problemas prácticos reales y obtener conclusiones para la mejor actuación de las potestades públicas ejercitadas en el ámbito de la protección del patrimonio histórico, particularmente en la declaración de bienes de interés cultural (BIC).

Partimos del carácter esencialmente técnico que revisten las potestades administrativas en este ámbito y de lo fundamentales que resultan los informes como base de la decisión administrativa. Piénsese que se trata de vertebrar una decisión administrativa aplicando conceptos de disciplinas o ciencias que nada tienen que ver con lo "jurídico".

Analizamos, a través de las sentencias, las técnicas de control empleadas por los tribunales, dado que éstos no pueden sustituir el juicio decisorio de la Administración por el suyo propio, pero sí han de comprobar que dicha actuación se mueve dentro de unos parámetros. Estas técnicas de control de actos calificados como de "discrecionalidad técnica" son el control por los "hechos determinantes", el control por el fín, y el control por los elementos reglados del acto.

\section{Palabras clave}

Actos administrativos / Administración pública / Bienes de interés cultural / Control jurisdiccional de la administración / Derecho administrativo / Discrecionalidad administrativa / Jurisprudencia / Patrimonio histórico / Protección / Seguridad jurídica

\section{INTRODUCCIÓN}

La peculiaridad del control judicial de la actuación administrativa en materia de protección del patrimonio viene justificada por la propia naturaleza de las potestades administrativas ejercidas en esta materia. Esta primera afirmación, como señala la profesora Concepción Barrero Rodríguez, no significa, sin embargo, que todas las potestades administrativas que se desarrollan en este ámbito hayan de calificarse dentro de la tipología de "potestades discrecionales", ya que la protección del patrimonio puede proyectarse a través de mecanismos tan distintos como la declaración de qué ha de considerarse bien de interés cultural; la configuración del concreto régimen de protección con la consiguiente autorización de actuaciones sobre bienes declarados de interés cultural; el eventual ejercicio de una actividad sancionadora para garantizar la defensa y protección de esos bienes 0 , finalmente, la actividad destinada a promocionar y fomentar la protección de estos bienes. Es incuestionable que las potestades ejercidas en los distintos planos referidos, aunque respondiendo a una misma vocación o finalidad, la de protección del patrimonio, no responden, sin embargo, a la misma naturaleza jurídica, ya que en unos casos las potestades ejercidas participarán más de la naturaleza de las Ilamadas "potestades discrecionales", en tanto que en otros de estos ámbitos (como son el sancionador o el de fomento) las potestades ejercidas responderán al concepto de "potestades regladas".

Lógicamente es cuando hablamos de discrecionalidad cuando el control judicial de esta actividad administrativa implica peculiaridades.

Ahora bien, hablar de discrecionalidad técnica en el ámbito del ejercicio de potestades administrativas en materia de protección del patrimonio exige, a su vez, la necesidad de realizar matizaciones, ya que dependiendo de la concreta figura de protección de la que estemos hablando, el margen de discrecionalidad del que goza la Administración resulta más o menos amplio.

Efectivamente, no nos encontramos ante el mismo margen de discrecionalidad cuando se trata de la declaración como bien de 
interés de cultural de una cueva con manifestaciones de arte rupestre, que cuando se declara como bien de interés cultural un bien inmueble, que se considera representativo por su valor histórico o artístico.

Es la propia norma la que propicia el ejercicio de distintas "escalas de discrecionalidad". Así, el artículo 15 de la Ley 16/1985 de patrimonio histórico español, dentro de los bienes inmuebles que pueden ser objeto de declaración, contempla ambos supuestos:

"1. Son monumentos aquellos bienes inmuebles que constituyen realizaciones arquitectónicas o de ingeniería, u obras de escultura colosal siempre que tengan interés histórico, artístico, científico o social (...).

5. Zona arqueológica es el lugar o paraje natural donde existen bienes muebles o inmuebles susceptibles de ser estudiados con metodología arqueológica, hayan sido o no extraídos y tanto si se encuentran en la superficie, en el subsuelo o bajo las aguas territoriales españolas".

En similares términos se pronuncia el artículo 26 de la Ley de patrimonio histórico de Andalucia, Ley 14/2007, de 26 de noviembre.

En el primer caso, es la propia ley la que declara bienes de interés cultural las cuevas, abrigos y lugares que contengan manifestaciones de arte rupestre, por lo que la potestad administrativa de declaración se desenvolverá en el margen técnico de la apreciación de si concurren los presupuestos fácticos contenidos en la ley para que ese bien inmueble reúna los requisitos que permiten ca- lificarlo como "zona arqueológica". Es decir, la apreciación técnica, aún participando de las notas de discrecionalidad, lo es a un nivel que podríamos calificar de mínimo, ya que los conceptos recogidos en la norma como definitorios de un bien de esta naturaleza gozan de una mayor precisión técnica.

Así, la Ley de patrimonio histórico español, 16/1985, en su artículo 40.2, señala: "2. Quedan declarados bienes de interés cultural por ministerio de esta Ley las cuevas, abrigos y lugares que contengan manifestaciones de arte rupestre".

En el segundo caso, la declaración de un inmueble como bien de interés cultural, por la consideración de que el mismo incorpora un valor relevante desde un punto de visto artístico o histórico, implica un grado de discrecionalidad mucho mayor, ya que el propio concepto de "valor histórico o artístico" supone per se un juicio valorativo, permítasenos la reiteración, que estará condicionado por el propio concepto que se maneje de lo que se entienda por relevante histórica o artísticamente.

La norma proporciona asi distintas escalas de discrecionalidad a la hora de la declaración de bienes inmuebles como bienes de interés cultural, discrecionalidad que exigirá al operador jurídico una mayor o menor fundamentación técnica o motivación, en el sentido administrativo, de su decisión.

Descendiendo al campo de los ejemplos, es claro o evidente que no es lo mismo declarar bien de interés cultural, en el concepto de zona arqueológica, una cueva, como es el caso de la cueva

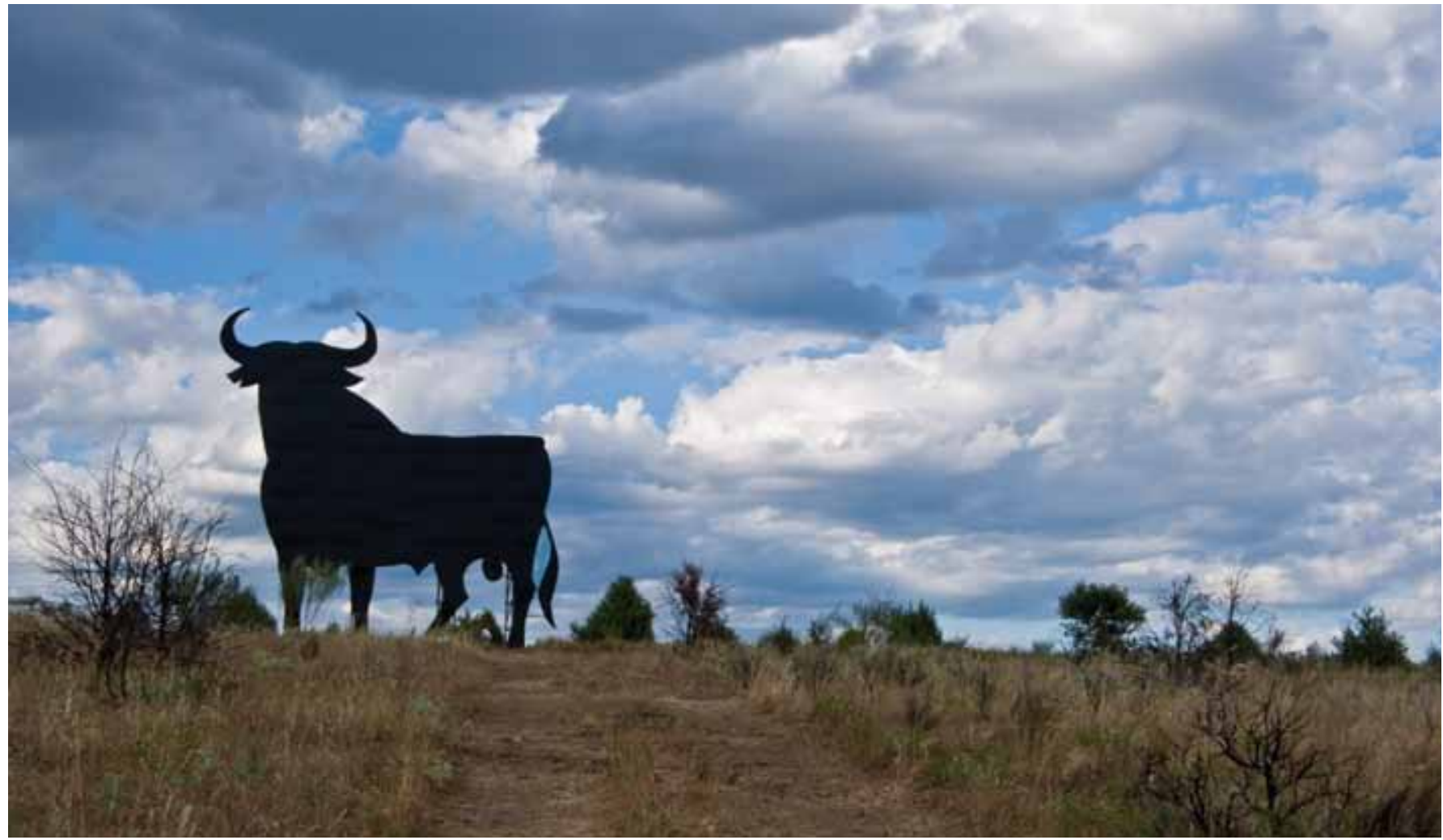

En 1957 apareció el primer Toro de Osborne en las carreteras españolas. Situado más o menos a la altura del km 55 de la Nacional I en el término municipal de Cabanillas de la Sierra (Madrid). Foto: Jorge Louzao Penalva 
de la Pileta, en el término municipal de Benaoján (Málaga), que declarar como BIC, con la categoría de monumento, las vallas publicitarias de los toros de Osborne.

Es pues, precisamente, ese margen de discrecionalidad técnica lo que caracteriza el ejercicio de las potestades administrativas que se ejercen por la Administración Pública cuando hablamos de la protección del patrimonio histórico. Ese juicio valorativo a la hora de determinar qué se considera como bien o valor cultural, para asi poder definir el marco en el que han de ejercitarse las potestades que el ordenamiento confiere para la protección del patrimonio, es lo que dota de unos perfiles o notas caracteristicas a esta actividad administrativa y, por ende, al control judicial que los tribunales ejercen sobre la misma.

\section{EL CONTROL JUDICIAL DE LAS POTESTADES ADMINISTRATIVAS EJERCITADAS EN LA PROTECCIÓN DEL PATRIMONIO HISTÓRICO}

\section{La naturaleza de las potestades que se ejercen en la protección del patrimonio histórico, especialmente en los procedimientos de declaración de bienes de interés cultural}

Toda la actividad administrativa se encuentra sujeta al control de los órganos judiciales. Esta premisa básica como punto de partida resulta esencial para el operador jurídico, que no puede perder de vista, en el ejercicio de sus funciones, que las potestades que ejerce en este contexto habrán de serlo siempre con la perspectiva de fundamentar debidamente la decisión administrativa tanto desde el punto de vista sustantivo o material, como desde el punto de vista formal o procedimental.

Los tribunales controlan la legalidad de la actuación administrativa y el sometimiento de ésta a los fines que la justifican, así proclama nuestro texto constitucional en su artículo 106, como no podía ser de otro modo en un Estado de Derecho, en el que la actuación administrativa, al servicio del interés general, se encuentra sometida al principio de legalidad, lo que supone que la Administración sólo puede hacer aquello que la ley le permite, y con la amplitud y los medios que el propio ordenamiento jurídico establece.

Por lo que al presente trabajo interesa, este sometimiento de la Administración a la ley y al Derecho, y el correlativo control de los tribunales del ejercicio de estas potestades administrativas en el ámbito de la protección del patrimonio histórico, nos ofrece unos perfiles característicos, precisamente por la naturaleza de las potestades administrativas que se ejercitan en este contexto, potestades de naturaleza esencialmente discrecional.

El control judicial de los actos administrativos en los que se ejercitan facultades discrecionales es uno de los ámbitos que más literatura juridica ha generado, fundamentalmente porque cuando hablamos del control judicial de estas potestades administrativas, tenemos que tener en cuenta que aún cuando no existe ámbito de la actuación administrativa que quede exento del control judicial, sí hemos de reconocer que el alcance de dicho control o revisión jurisdiccional no es el mismo que cuando ese control se realiza o efectúa respecto a la actuación administrativa en la que se ejercen potestades regladas. Efectivamente, en este ámbito de control judicial, los tribunales, como veremos posteriormente, pueden declarar la nulidad de la actuación administrativa revisada, pero no pueden sustituir el criterio de la Administración por el suyo propio o, como más precisamente señala la Ley 29/1998, de 13 de julio, reguladora de la jurisdicción contencioso-administrativa, en su artículo 71.2, "2. Los órganos jurisdiccionales no podrán determinar la forma en que han de quedar redactados los preceptos de una disposición general en sustitución de los que anularen ni podrán determinar el contenido discrecional de los actos anulados".

La distinción tradicional entre las llamadas potestades administrativas regladas y las potestades administrativas discrecionales radica, en esencia, en el distinto margen de apreciación con que cuenta la Administración a la hora del ejercicio de unas y otras.

En las potestades regladas, el papel que desempeña la Administración cuando las ejercita consiste en la comprobación de la realidad y subsunción de ésta en el presupuesto de hecho contemplado en la norma y aplicación de consecuencias jurídicas.

En el ámbito de las potestades discrecionales, el papel de la Administración varia, ya que la Administración cuenta con una facultad de elección entre diversas alternativas, todas validas y posibles, y la selección obedece a razones de oportunidad.

Entre ambas categorías, y como intermedia, nos encontrariamos con aquellas potestades que, en principio, participando de la naturaleza de las potestades regladas, sin embargo, para su ejercicio precisan de un juicio valorativo e interpretativo, de carácter técnico, que es el determinante a la hora del ejercicio de la potestad; serian las potestades en la llamada discrecionalidad técnica.

Pues bien, en este contexto, las potestades administrativas en materia de cultura y, especialmente, en los procedimientos de declaración de bienes de interés cultural, participan inicialmente del carácter de potestades regladas, en la medida en que se trata de declarar como bienes de interés cultural a aquellos inmuebles que reúnen las caracteristicas señaladas por la ley; sin embargo, esta primera conclusión se desdibuja cuando observamos que el "carácter jurídico indeterminado" de los conceptos en que se asientan las definiciones legales, hace preciso:

1. Un juicio basado en aportaciones de disciplinas no juridicas (técnicas). La historia, el arte, la arqueología.

2. Un juicio valorativo entre varios posibles.

3. Un juicio en el que prima la razón técnica, no de oportunidad. 
Por tanto, estamos ante el ejercicio de potestades de "discrecionalidad técnica" donde el margen de apreciación técnica del que goza la Administración podrá ser mayor o menor, en función de la caracterización legal que se haga del tipo de bien de interés cultural.

Efectivamente, como hemos señalado al comienzo de este estudio, no es lo mismo el ámbito valorativo que se ofrece a la Administración a la hora de declarar como bien de interés cultural, en la categoría de monumento, unas vallas publicitarias como son los toros de Osborne, que cuando se trata de declarar como zona arqueológica una cueva en la que se han verificado hallazgos de arte rupestre.

Existen por tanto, lo que se ha dado en denominar, escalas de la discrecionalidad.

Sobre el ejercicio de estas potestades, se proyecta pues el control de los tribunales buscando el necesario equilibrio entre la necesidad de control en sí misma, como garantía de seguridad jurídica en un Estado de Derecho, y la imposibilidad de sustituir el juicio eminentemente técnico de la Administración, en la aplicación de conceptos y disciplinas que, evidentemente, nada tienen de jurídicas.

\section{Las técnicas de control de la actividad discrecional y su aplicación en el ámbito de la declaración de los BIC}

La necesidad de control judicial del ejercicio de estas potestades administrativas, ya lo hemos anticipado, es una garantía de seguridad juridica y de equilibrio entre la obligación que pesa sobre los poderes públicos en los términos del artículo 46 de la Constitución Española, cuando señala que "Los poderes públicos garantizarán la conservación y promoverán el enriquecimiento del patrimonio histórico, cultural y artístico de los pueblos de España y de los bienes que lo integran, cualquiera que sea su régimen juridico y su titularidad"; y la limitación e injerencia que para la esfera jurídicopatrimonial de los titulares de los bienes declarados como de interés cultural puede implicar dicha declaración.

Aunque en su ejercicio, como hemos visto, se mezclen aspectos técnicos extrajurídicos y aspectos jurídicos en sentido estricto, ello no impide la revisión jurisdiccional de estos actos, garantizando asi el pleno sometimiento a la ley y al Derecho, como señala el artículo 106 de la Constitución, así como el servicio con objetividad de los intereses generales, como asimismo señala el artículo 103 de nuestro texto fundamental, haciendo posible que también en este ámbito, los ciudadanos tengan asegurado el acceso a los jueces y tribunales para obtener de ellos la efectiva tutela de sus derechos e intereses legítimos, desterrando la indefensión, en los términos contemplados en el artículo 24 del mismo cuerpo legal.

Discrecionalidad no es arbitrariedad y ésta se encuentra expresamente prohibida en nuestro ordenamiento juridico. Hablamos de la interdicción de la arbitrariedad a que se refiere la Constitución en su artículo 9.3, como uno de los principios fundamentales de nuestro ordenamiento jurídico y que supone la prohibición de que los poderes públicos actúen conforme a la mera voluntad de sus titulares, sin ajustarse a las normas. En el Estado de Derecho rige el imperio de la ley, a la que están sujetos todos los poderes. La arbitrariedad, la actuación sin fundamento jurídico, está prohibida en un Estado de Derecho.

Este principio, establecido en el artículo 9.3 de la Constitución, significa que las autoridades no pueden tomar decisiones arbitrarias, entendiéndose por tales fundamentalmente aquéllas que supongan una infracción del principio de igualdad de trato de los administrados ante la aplicación de la ley y las reglas objetivamente determinadas.

Los tribunales de justicia utilizan este principio constitucional de "interdicción de la arbitrariedad" para impedir que los poderes públicos sostengan interpretaciones arbitrarias de las normas (sentencias del Tribunal Constitucional 219/1989 y 93/1992) o resoluciones abiertamente discriminatorias (por ejemplo, sentencia del Tribunal Supremo de 19 de junio de 2002). Como dice expresivamente el Tribunal Constitucional en su sentencia 151/1986, "a la luz de lo indicado ha de concluirse que a lo largo del procedimiento administrativo los ciudadanos han sido objeto, efectivamente, de un trato desigual respecto a otros en situación similar, sin que se haya razonado o justificado el por qué de esa desigualdad... Pues no resulta admisible -ni por tanto debe considerarse justificativo de la desigualdad-que la Administración elija libremente a quiénes aplicar y a quiénes no aplicar la normativa vigente, actuación esta vetada por la interdicción de la arbitrariedad contenida en el art. 9.3 de la Constitución".

Veamos pues en concreto cuáles son las técnicas empleadas por los tribunales para controlar la actuación administrativa cuando ésta, la Administración, ejerce potestades administrativas en materia de protección del patrimonio histórico y, muy especialmente, cuando se trata de declarar bienes de interés cultural.

Las distintas técnicas de control de la actividad discrecional en la declaración de los BIC, análisis de algunas de las sentencias más relevantes en el ámbito de la comunidad autónoma de Andalucía

\section{- El control de la discrecionalidad técnica a través del control de los hechos determinantes}

El control de los hechos determinantes consiste en que los tribunales, a la hora de controlar la legalidad y adecuación a Derecho de la actuación administrativa consistente en la declaración de un bien como de interés cultural (BIC), lo que hacen es comprobar si existe el presupuesto de hecho que en la norma legitima el ejercicio de la potestad.

Es decir, se trata, a través de esta técnica, de constatar si la declaración como BIC de un determinado inmueble, en una de las 
concretas categorías o clases que contiene la ley, en nuestro caso la Ley 14/2007 de patrimonio histórico de Andalucia, en su artículo 26 (monumento, conjunto histórico, jardines históricos, zonas arqueológicas, lugares de interés etnológico, lugares de interés industrial o zonas patrimoniales), se encuentra justificada o motivada por reunirse, efectivamente, y acreditarse en el expediente administrativo tramitado al efecto "que concurren los requisitos que en el texto legal configuran las nota que definen al concreto tipo de BIC elegido".

Pensemos que la base de esta técnica radica en el hecho de que las potestades administrativas conferidas por el ordenamiento jurídico a la Administración se ejercen bajo el principio de legalidad, que desde la perspectiva que aquí nos interesa supone que el ejercicio efectivo de dicha potestad tiene que justificarse en que concurre la base fáctica que la norma ha configurado como presupuesto para entender que ese determinado bien es acreedor de la protección establecida por la ley.

Efectivamente, como se puede imaginar, el problema procesal esencial que se nos plantea desde la perspectiva de esta técnica de control se desplaza al ámbito de la motivación o fundamentación de la decisión administrativa y, por tanto, a la suficiencia de la prueba técnica que acredita la concurrencia efectiva de los presupuestos fácticos contenidos en la norma, determinantes de la protección otorgada.

Debe existir pues, en el expediente administrativo tramitado al efecto, una motivación o justificación técnica suficiente de la decisión administrativa para despejar con ello cualquier duda de arbitrariedad de la decisión. La Administración tiene que justificar técnicamente la correcta integración del concepto jurídico indeterminado que emplea la norma.

Los informes técnicos, fundamento de la decisión administrativa, cobran en esta perspectiva de control un papel esencial. Su existencia y constancia en el expediente administrativo, como base de la decisión tomada, son el elemento probatorio acreditativo de la racionalidad técnica de la decisión.

Es importante destacar el dato apuntado de que la fundamentación o motivación técnica debe existir en el expediente administrativo tramitado al efecto, es decir, debe ser el prius del acto administrativo, no la justificación a posteriori. No podemos confundir "motivar" la decisión administrativa con "justificar" la decisión tomada.

Hemos querido resaltar esta diferencia entre motivar y justificar, porque la misma no es una mera cuestión terminológica; es, por el contrario, la esencia de cara al ejercicio de la potestad administrativa que el ordenamiento confiere. Por ello, el defecto en la motivación técnica obrante en el expediente administrativo tramitado al efecto no se salva con la aportación posterior, en fase probatoria judicial, de informes que justifiquen el acierto técnico

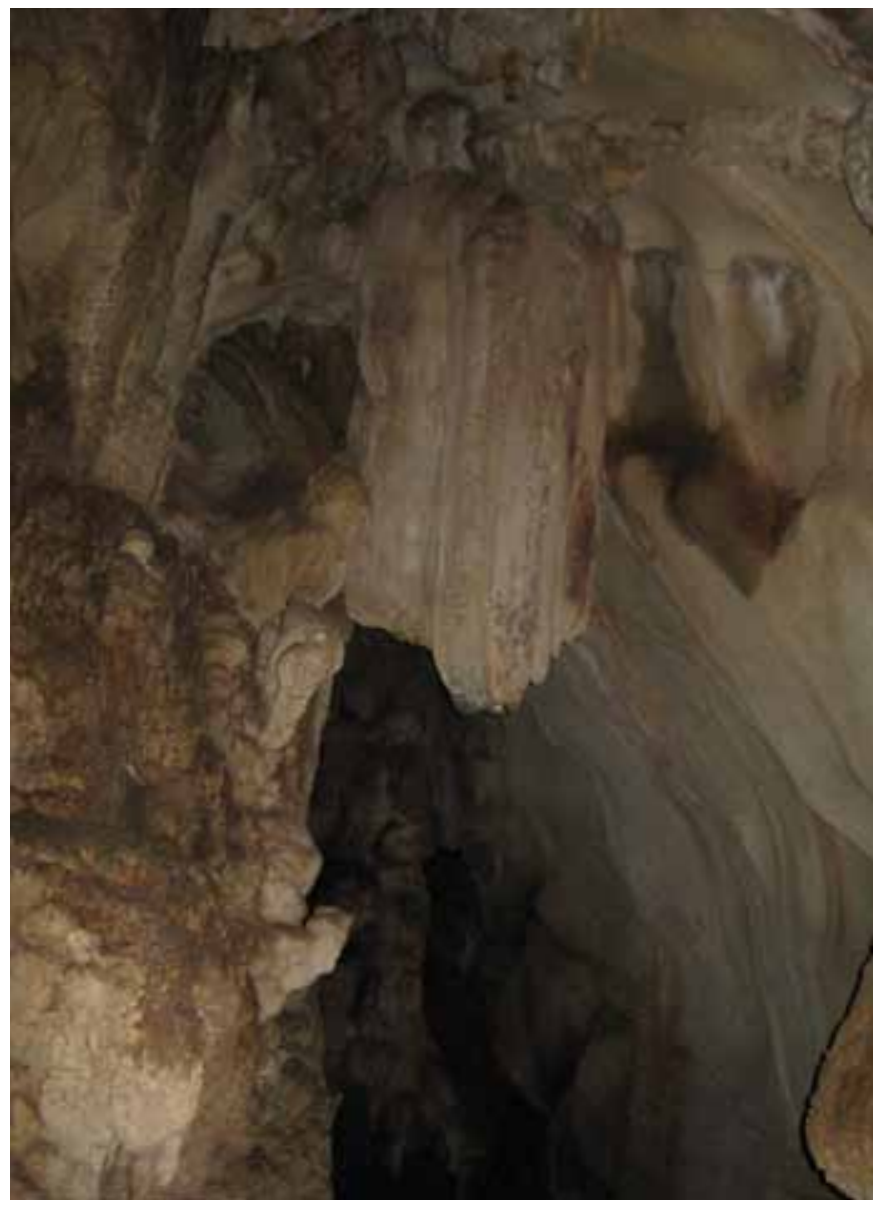

Cueva de la Pileta. Foto: Lia Vas

\section{La naturaleza esencialmente discrecional de las potestades administrativas en el ámbito de protección del patrimonio histórico dota de unos perfiles característicos el sometimiento de la Administración a la ley y al Derecho y el correlativo control de los tribunales}

de la decisión, sino que ese acierto técnico es previo. El bien se declara por tanto como de interés cultural porque técnicamente queda debidamente justificado que en el mismo concurren los requisitos que la norma ha establecido para considerarlo digno de la especial protección que supone la declaración administrativa. Los informes técnicos son la base previa de la decisión, que en este iter temporal y lógico es el resultado o consecuencia de los mismos, no a la inversa.

Son muchos los ejemplos del alcance de esta técnica de control judicial que podriamos citar en este trabajo, de hecho es éste uno de los puntos de batalla más empleados a la hora de discutir la decisión administrativa de declaración de BIC. 
En el contexto del proceso judicial, cuando el recurrente o demandante discute la legalidad de la actuación administrativa desde esta perspectiva, surge la carga procesal de probar que la Administración se ha excedido a la hora de ejercitar la potestad administrativa, cuestionando la suficiencia de la motivación técnica empleada.

En este análisis, el tribunal examina la efectiva existencia o no de la motivación o fundamentación técnica de la decisión administrativa y de la racionalidad de la decisión en función de la existencia de los informes que avalan la misma, informes que reiteramos han de ser previos a la decisión adoptada.

En sentencia de 29 de junio de 2007, la Sala de lo ContenciosoAdministrativo del Tribunal Supremo, al resolver el recurso de casación 5742/2001, interpuesto frente a sentencia de 28 de marzo de 2001 de la Sala de lo Contencioso-Administrativo del Tribunal Superior de Justicia de Andalucia, con sede en Sevilla, aborda este extremo. El recurso en la instancia desestimaba la demanda interpuesta frente al Decreto por el que se delimitaba el ámbito afectado por la declaración de bien de interés cultural, con la categoría de zona arqueológica, del yacimiento denominado cueva de la Pileta. El demandante impugna el citado Decreto porque la delimitación del entorno de la cueva realizada por la Administración incidia en su esfera patrimonial ya que afectaba a una finca de su propiedad, implicando las correspondientes limitaciones o cargas derivadas del régimen de protección legal.

Entre los distintos vicios que denunciaba el recurrente, se encontraba la pretendida falta del presupuesto de hecho, ya que para el actor no se encontraba debidamente motivada la decisión administrativa de delimitar el entorno de la cueva.

El Tribunal Supremo, que desestimó el recurso de casación, confirmando la adecuación a Derecho de la actuación de la Junta de Andalucía, en el fundamento jurídico tercero de la sentencia, rechaza las infracciones normativas denunciadas y la pretendida falta de presupuesto de hecho sobre la base de que la legislación aplicable, la Ley de patrimonio histórico español, artículo 40.2, declara bien de interés cultural por ministerio de la ley, las cuevas, abrigos y lugares que contengan manifestaciones de arte rupestre, y que es también la ley la que prevé que, en el caso de declaración de un inmueble como BIC, se delimite el entorno afectado por la declaración, entorno que deberá asimismo concretarse en la inscripción específica en el Catálogo General de Patrimonio Histórico Andaluz y entorno al que le será de aplicación el mismo régimen jurídico que corresponda al inmueble catalogado.

Constatada la existencia de la cueva y la presencia en ella de restos arqueológicos y de pinturas rupestres, al Tribunal Supremo no le cabe duda de la concurrencia del presupuesto fáctico que habilita a la Administración para la delimitación del entorno del bien: "la Administración puede iniciar un expediente para delimitar el entorno de dicha cueva, para asegurar su adecuada protección, pues resulta evidente que las actuaciones que se efectúen en las inmediaciones de los bienes de interés cultural pueden entrañar o suponer un peligro para su conservación. Hemos de concluir que existía el presupuesto necesario para la incoación del procedimiento".

No nos parece baladí insistir en la necesidad de que los informes técnicos emitidos en el contexto que nos ocupa resultan esenciales a la hora de la defensa de la actuación administrativa cuando se trata, como en nuestro caso, del ejercicio de potestades caracterizadas por la incidencia de los aspectos técnicos extrajurídicos y correspondientes a disciplinas muy diferentes. Es precisamente la exigencia de esta fundamentación técnica en el dictado del acto la que imposibilita que el tribunal pueda sustituir el criterio técnico seguido por la Administración cuando éste aparece fundamentado y no se desvirtúa, por la prueba practicada a instancias de la parte demandante, la racionalidad de la decisión.

En este mismo sentido podemos citar la Sentencia de la Sección Primera de la Sala de lo Contencioso-Administrativo de Sevilla del Tribunal Superior de Justicia de Andalucía de 28 de octubre de 2009, cuyo fallo desestima el recurso n. ${ }^{\circ} 1015 / 2004$, interpuesto contra la Orden de la Consejeria de Cultura por la que se acordaba inscribir, con carácter genérico, en el Catálogo General del Patrimonio Histórico Andaluz, la casa Palacio sita en el número 45 de la calle Juan Carlos I de Peñaflor (Sevilla). Frente a la alegación del recurrente de que la Administración se había basado, a la hora de inscribir en el catálogo, exclusivamente "en el estado y caracteristicas de la fachada, ya que en otras partes de la casa se han llevado a cabo obras que no han sido tenidas en cuenta". A ellos, la sala responde "Pues bien, aunque fuera así, ello no sería óbice para una catalogación que aparece justificada en el expediente con documentación técnica que la parte no ha logrado desvirtuar con otra mejor fundada que convenza de la improcedencia de la catalogación".

Creemos importante, en este punto, destacar varias conclusiones de relevancia en relación con los aspectos procesales.

De un lado, en lo que a la prueba se refiere, es importante tener en cuenta que los informes técnicos que sustentan o motivan la decisión administrativa adoptada han de formar parte en todo caso del expediente administrativo, ya que como hemos expuesto, constituyen el prius del acto administrativo. Frente a los mismos, se proyectará en su caso la prueba propuesta y practicada a instancias de la parte actora. Frente a dicha prueba, la administración demandada podrá practicar nuevas pruebas, aportando en su caso informes técnicos, pero los mismos se entienden desde la perspectiva de desvirtuar la prueba practicada a instancias de la actora, pero no para motivar la decisión administrativa tomada. De la confrontación entre ambas pruebas, el Tribunal de Instancia formará su convicción sobre la existencia o no de los hechos determinantes en los términos y con el alcance que venimos exponiendo.

Esta valoración de la prueba realizada por el Tribunal de Instancia no puede ser revisada por el tribunal ad quem. Es decir, ni en el 


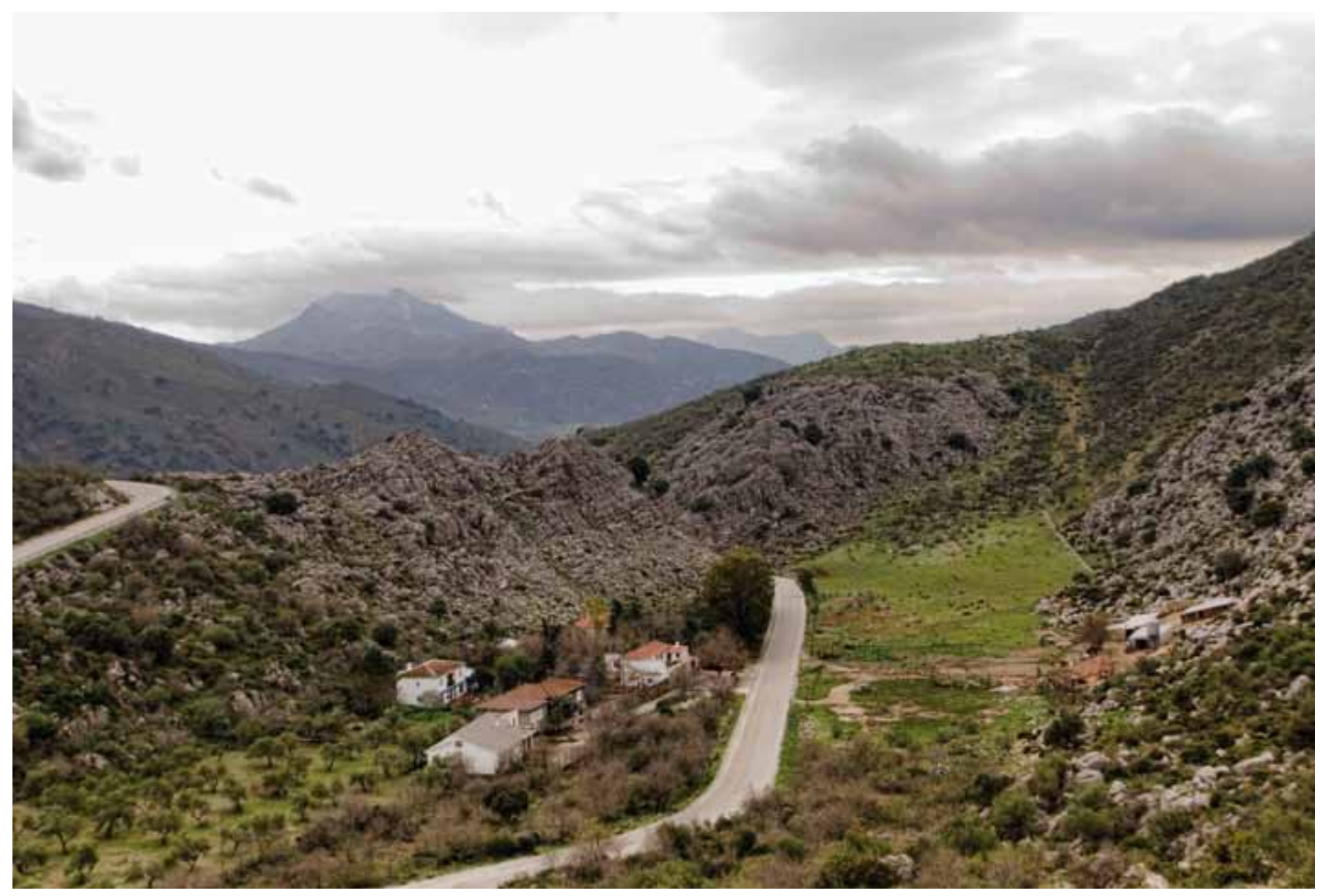

La delimitación del entorno del yacimiento denominado cueva de la Pileta afectado por la declaración de BIC generó un recurso de casación ante el Tribunal Supremo interpuesto por el propietario de una finca de las inmediaciones. Foto: Antonio Carrasco, El Saucejo

recurso de apelación ni en el de casación es posible la revisión de la valoración de la prueba realizada por el Tribunal de Instancia, por lo que hay un momento preclusivo, procesalmente hablando, para probar aquellos aspectos fácticos que, al margen de lo que es propiamente la motivación estricta del acto, hayan de ser objeto de prueba y consiguiente valoración.

Resaltamos este aspecto porque es, además, una de las cuestiones que suele abordar el Tribunal Supremo al conocer de los recursos de casación en los que se pretende discutir la conclusión alcanzada por el tribunal a quo cuando examina y revisa la actuación administrativa desde la perspectiva de la concurrencia de los hechos determinantes.

En sentencia de 15 de noviembre de 2011 dictada en el Recurso de Casación n. ${ }^{0}$ 761/2010, la Sala de lo Contencioso-Administrativo del Tribunal Supremo desestima el recurso interpuesto por la Junta de Andalucía contra la sentencia de la Sala de lo Contencioso-Administrativo de Sevilla del Tribunal Superior de Justicia de Andalucía recaida en el recurso n. ${ }^{\circ}$ 830/2006. En la instancia, el Tribunal Superior de Justicia, estimando el recurso, anula la resolución de la Dirección General de Bienes Culturales, por la que se acordaba inscribir colectivamente, con carácter genérico, en el Catálogo General del Patrimonio Histórico Andaluz, 43 yacimientos arqueológicos del término municipal de Estepa.
En la sentencia recurrida, el Tribunal de Instancia anulaba la resolución recurrida por considerar que "en el expediente administrativo no existe documento o estudio técnico alguno que revele la existencia de yacimiento arqueológico en las fincas de la propiedad de las actoras. La única documentación técnica obrante, consiste en una descripción de los yacimientos efectuada por la Delegación Provincial, pero en la misma únicamente constan unas afirmaciones de vestigios encontrados, sin indicación de los técnicos que lo efectuaron, carente de toda, firma, y sin indicación de los estudios realizados y procedimiento seguidos para llegar a la afirmación que sustenta y a la calificación de existencia de yacimientos arqueológicos. Dicha ausencia de identificación de los técnicos que la efectuaron, su cualificación técnica y la explicación del método seguido priva al informe de cualquier eficacia probatoria de la existencia de yacimiento.

Al margen de dicha documentación, la decisión sólo se sustentaría en un informe de la Comisión Provincial de Patrimonio Histórico de 30/3/05, que se limita a reproducir un informe de la Conservadora de Patrimonio, que hace referencia a una prospección arqueológica efectuada en 1998 y 1999; pero dicha prospección no se encuentra en el expediente administrativo, ni se indica el método de hacerla y los resultados concretos.

En definitiva, en el expediente administrativo no existe documentación técnica alguna que permita constatar la realidad de 
la existencia de los yacimientos arqueológicos, en las fincas de los recurrentes, que justifiquen la inscripción, practicada, por lo que el recurso ha de ser estimado" (sic).

Frente a la citada sentencia, el Gabinete Jurídico de la Junta de Andalucia procedió a anunciar e interponer recurso de casación. Dada la imposibilidad de la revisión de la valoración de la prueba en sede casacional, el recurso se articuló con invocación, al amparo del artículo 88.1.d) de la Ley reguladora de la jurisdicción contencioso-administrativa, de la infracción de las normas reguladoras de la prueba, en concreto se denunciaba la infracción del artículo 319.2 de la Ley de enjuiciamiento civil, y que el Tribunal de Instancia no había valorado de forma contradictoria la prueba sobre la realidad de los yacimientos que obraba en el expediente frente a la aportada de contrario, realizando con ello una inversión de la carga de la prueba, ya que, sosteníamos, es la actora la que debería desvirtuar el contenido de la documentación técnica existente. Asimismo denunciábamos que se habian vulnerado por el tribunal a quo las reglas que rigen la valoración de la prueba, en particular la que impone valorarla conforme a la sana crítica, de forma racional y no arbitraria.

Frente a este planteamiento, el Tribunal Supremo expresamente señala en la referida sentencia que:

"Las alegaciones de la parte obligan, a realizar un repaso a la doctrina que esta Sala viene aplicando, frente a los intentos de impugnación de la actividad probatoria realizada por los Tribunales de instancia. Retomando lo dicho en sentencia de 23 de febrero de 2010, recurso 1760/2008, hay que sentar como premisa que la posibilidad de revisar cuestiones relacionadas con la prueba en el ámbito casacional se encuentra absolutamente limitada. No debe olvidarse que la finalidad del recurso, es uniformar la interpretación del ordenamiento juridico por lo que no cabe revisar la valoración de la prueba realizada por la Sala de instancia a la que incumbe tal función sin que este Tribunal constituya una segunda instancia. Por ello, este Tribunal insiste en que no corresponde al mismo en su labor casacional revisar la valoración de la prueba efectuada por la Sala de instancia ante el mero alegato de la discrepancia en la valoración efectuado por la parte recurrente.

Constituye así jurisprudencia reiterada (STS de 26 de septiembre de 2007, recurso de casación 9742/2003, con mención de otras muchas anteriores) identificar como 'temas probatorios que pueden ser tratados en casación', esto es, como temas directa ó indirectamente relacionados con la prueba que, sin embargo, sí son susceptibles de ser abordados o revisados en casación, sólo unos pocos. Así: (1) la vulneración de las reglas que rigen el reparto de la carga de la prueba; (2) la indebida denegación, bien del recibimiento del pleito a prueba, bien de alguno o algunos de los medios de prueba propuestos; (3) la infracción de las normas relativas a la prueba tasada o a la llamada prueba de presunciones; (4) la infracción de las reglas de la sana crítica cuando la apreciación de la prueba se haya realizado de modo arbitrario o irrazonable o conduzca a resultados inverosimiles; (5) la infracción cometida cuando, al socaire de la valoración de la prueba, se realizan valoraciones o apreciaciones erróneas de tipo jurídico; (6) los errores de este tipo cometidos en los dictámenes periciales, documentos o informes, que, al ser aceptados por la sentencia recurrida, se convierten en infracciones del ordenamiento juridico imputables directamente a ésta; y (7) por último, la integración en los hechos admitidos como probados por la Sala de instancia de aquellos otros que, habiendo sido omitidos por ésta, estén suficientemente justificados según las actuaciones y cuya toma en consideración resulte necesaria para apreciar la infracción alegada" (sic).

Tras recoger la fundamentación transcrita, la sentencia del Tribunal Supremo desciende al análisis de nuestro recurso y acaba desestimando el mismo porque entiende que la sentencia recurrida llevó "a cabo una valoración de la documentación obrante en el expediente, que condujo a la conclusión de la falta de justificación de lo que habria dar lugar a la inscripción de un yacimiento, que no acredita que lo efectuase con error patente, ni de modo arbitrario o irracional, por el suceso que la perito haya contestado con 'es posible' la pregunta de si fuera posible encontrar una mayor cantidad de restos arqueológicos tras una inspección realizada con más tiempo y con empleo de mecanismos científicos, pues pudiendo ser ello así, es lo cierto que la conclusión de la sentencia no se refiere a la inscripción que pueda resultar de justificarse la existencia de restos arqueológicos de interés relevante tras la realización de aquélla prospección, como la falta de justificación de presente de esto mismo respecto las fincas de los recurrentes, sin que sea posible sustituir la valoración de la Sala de instancia por la reputada más acertada, por el recurrente, tal como reiteradamente sostiene este Tribunal" (sic).

Hemos querido transcribir los fundamentos anteriores a fin evidenciar la problemática procesal que, desde la perspectiva probatoria suscitan los procedimientos judiciales como los que nos ocupan, en los que se revisa la actuación de la Administración cuando ejercita estas potestades calificables como de discrecionalidad técnica. Los informes resultan esenciales para acreditar la existencia de motivación o fundamentación de la decisión administrativa; deben formar parte imprescindible del procedimiento administrativo tramitado al efecto, ya que constituyen un prius en la decisión administrativa; son esenciales a la hora del control judicial de la concurrencia de los hechos determinantes; su carencia no puede ser suplida por una justificación a posteriori, ya que justificar no es lo mismo que motivar y, por último, la valoración de la prueba realizada por el Tribunal de Instancia en orden a formar su convicción sobre la concurrencia de los presupuestos fácticos relevantes de cara al control de los denominados "hechos determinantes" no puede ser revisada ni en la segunda instancia ni, particularmente, en sede casacional, ya que dicha valoración sólo sería excepcionalmente revisable si incurriera en infracción de las normas reguladoras de la prueba o implicara una conclusión irracional e ilógica. 
Para terminar este apartado, queremos destacar el hecho, ya anticipado, de que el efecto o consecuencia jurídica de la revisión de la decisión administrativa ejerciendo potestades de discrecionalidad técnica, cuando el tribunal estima que no concurren los hechos determinantes, no puede ser otro que la anulación de la actuación administrativa, nunca su sustitución por el criterio del tribunal sentenciador.

\section{- El control de los actos en esta materia, a través del fin}

El análisis de esta técnica de control de los actos administrativos caracterizados por la presencia de la discrecionalidad técnica tiene como punto de partida el dato esencial de que cuando el ordenamiento jurídico confiere a la Administración Pública el ejercicio de una potestad administrativa, dicha atribución se hace para que, mediante el ejercicio de la potestad, se consiga un determinado fin. Precisamente es la consecución de ese fin lo que legitima o justifica el ejercicio de la potestad conferida.

En palabras coloquiales, podríamos traer a colación la famosa cita de que el fin justifica los medios, no en el contexto representativo del maquiavelismo, sino en el más benévolo de que el fin lícito sí justifica los medios.

Partiendo pues de la idea que hemos reiterado en el presente trabajo de que las potestades administrativas se ejercen conforme al principio de legalidad y con sometimiento pleno a la ley y al Derecho, habriamos de concluir que dicha configuración legal del fin para el que se otorga o confiere la potestad administrativa es un fin legítimo o justo. Lógicamente en este contexto, la discusión sobre la adecuación de la ley a la Constitución y al resto del ordenamiento jurídico desplazaría el problema de la justicia formal de la potestad a una cuestión vinculada con la propia constitucionalidad de la ley. Pero es claro que mientras la ley esté vigente y su constitucionalidad no sea cuestionada, ha de concluirse en la licitud del fin que la norma legal contemple.

Ciertamente suele ser frecuente invocar, a la hora de la impugnación de la actuación administrativa en el ejercicio de potestades vinculadas a la protección del patrimonio histórico, que las mismas resultan inconstitucionales en la medida en que implican una injerencia en el patrimonio del titular del bien sobre el que recae la medida de protección, con clara lesión a derechos constitucionales como el derecho a la propiedad privada reconocido en el artículo 33 del texto constitucional o el derecho a la igualdad y prohibición de trato discriminatorio ex artículo 14 del mismo cuerpo legal.

Sin embargo, cuando hablamos de esas eventuales lesiones a derechos constitucionalmente reconocidos no estamos cuestionando propiamente "el fin para cuya consecución se confiere la potestad administrativa", sino el carácter especialmente lesivo de la actuación administrativa o la discriminación que la misma supone respecto a otros propietarios, con independencia de que el fin en sí mismo pueda ser legítimo.
Cuando los tribunales realizan el control judicial de la actuación administrativa y de las potestades conferidas en el ámbito de la protección del patrimonio histórico lo que realmente están comprobando no es si el fin en sí mismo es o no legítimo en los términos concebidos por el legislador, ya que si dudaran de la constitucionalidad de la ley aplicable al caso habrian de plantear la cuestión de inconstitucionalidad, como señala el artículo 5 de la Ley Orgánica del Poder Judicial; sino que lo que controlan es si la Administración ha hecho uso de la potestad conferida por el ordenamiento jurídico para cumplir el fin legalmente previsto y legitimador de la atribución de la potestad, o por el contrario se ha servido de la potestad conferida por el ordenamiento para fines distintos.

La desviación de poder se configura, desde la perspectiva que venimos analizando, como el vicio invalidante por antonomasia cuando hablamos del control judicial de los actos de discrecionalidad técnica a través del fin.

A la desviación de poder se refiere como vicio de anulabilidad del acto administrativo el artículo 63.1 de la Ley 30/1992, de régimen jurídico de las administraciones públicas y del procedimiento administrativo común, de 26 de noviembre, y, por su parte, la Ley 29/1998, reguladora de la jurisdicción contencioso-administrativa de 13 de julio 1998, en su artículo 70, entiende por desviación de poder "el ejercicio de potestades administrativas para fines distintos de los fijados por el ordenamiento jurídico".

En esta labor de control judicial de la actuación administrativa por el fin, se analizan los siguientes aspectos:

- Que el objetivo de la Administración Pública al ejercer la potestad pueda subsumirse en la finalidad para la que el ordenamiento atribuía la potestad.

- Que el medio por el que se ha optado para el cumplimiento de ese fin para el que se confiere la potestad sea proporcional a la finalidad perseguida.

- Que la medida adoptada para lograr el fin sea la idónea.

Efectivamente, en este contexto vuelve a tener sentido la cita empleada (¿el fin justifica los medios?), ya que incluso asumiendo la legitimidad y licitud del fin para el que se confieren las potestades administrativas en el ámbito de la protección del patrimonio histórico, es necesario que la medida adoptada reúna además las notas de idoneidad y proporcionalidad.

Aunque la finalidad del ejercicio de la potestad sea la de garantizar la conservación, protección y promoción del patrimonio histórico, no podemos obviar la evidente incidencia en cuanto a limitación de facultades inherentes al derecho de propiedad que puede implicar la declaración como bien de interés cultural de un bien mueble o inmueble para su titular. Ahora bien, acreditadas que sean la idoneidad y proporcionalidad de la medida, la efectiva lesión o incidencia en el derecho de propiedad no es contraria a Derecho toda vez que la función social que cumple 
la propiedad es la que delimita su contenido esencial, por lo que sólo si la lesión fuera especialmente individualizable para una persona, implicando una lesión singularmente caracterizada, habria lugar a plantear la fijación de una eventual indemnización compensatoria de esa lesión individualizada, al objeto de evitar un tratamiento discriminatorio. Pero, insistimos, esto no convertiría en contraria a Derecho la actuación administrativa revisada, sino que, en su caso, implicaría una eventual responsabilidad patrimonial.

En este sentido, resulta interesante la lectura de la sentencia del Tribunal Supremo, de la Sección Cuarta de la Sala de lo Contencioso-Administrativo, de 15 de diciembre de 2010, dictada en el recurso de casación n. ${ }^{\circ}$ 1336/2009. En ella el Tribunal Supremo concluye estimando el recurso y declarando haber lugar a la reclamación de responsabilidad patrimonial que habia deducido la mercantil actora, el día 25 de octubre de 2003, por los daños causados en su patrimonio con la aprobación y publicación del Decreto 321/2003, de 18 de noviembre, del Consejo de Gobierno de la Junta de Andalucia, que al declarar bien de interés cultural, con la categoría de zona arqueológica, las factorías romanas de salazones de Algeciras (Cádiz), arrastró como consecuencia que no pudiera hacer suyo el aprovechamiento urbanistico previsto para el solar de su propiedad.

La mercantil recurrente en casación, entre otros motivos de su recurso, denunciaba, al amparo de la letra d) del artículo 88.1 de la Ley 29/1998, de la jurisdicción contencioso-administrativa, la infracción de los artículos 139 y 141 de la Ley 30/1992, pues la actora habría sufrido, como afirmaba, una lesión patrimonial al verse privada del aprovechamiento urbanístico que correspondia a su terreno, que, aun siendo legitima, en cuanto derivada de la normativa de protección y conservación del patrimonio histórico artístico, no estaba obligada a soportar a expensas de su solo patrimonio.

En su sentencia, el Tribunal Supremo estima la pretensión indemnizatoria sobre la base de que "al tiempo de producirse la declaración del bien de interés cultural y de frustrar con ello aquel proyecto urbanizador, habia pasado a formar parte del contenido urbanístico del derecho de propiedad del suelo, el derecho a materializar el aprovechamiento urbanístico que correspondia al mismo.

Por ende, la privación de ese derecho, aunque amparada por la aplicación de las normas sobre protección del patrimonio histórico, no deja de constituir una lesión antijurídica y como tal indemnizable, pues el propietario de dicho suelo no tiene el deber jurídico de soportar el daño que a él en concreto le produce esa protección en interés y beneficio de la colectividad".

Por otra parte, es importante destacar que el control judicial del ejercicio de la potestad discrecional por el fin, íntimamente ligado, como se ha expuesto, con el vicio de anulabilidad de desviación de poder, plantea desde la perspectiva procesal el problema de la prueba de la concurrencia de la pretendida desviación.

Efectivamente, el control de la desviación de poder por parte de los tribunales de lo contencioso-administrativo resultaría muy dificil si se exigiera una prueba plena y exhaustiva de la existencia de dicha desviación de poder, lo cual convertiria la prueba en prácticamente diabólica si tenemos en cuenta que la desviación de poder puede obedecer a móviles que se desarrollan en la, digamos, esfera interna de quien comete la desviación de poder. Es por ello por lo que se permite que los tribunales estimen la existencia de desviación de poder cuando el juzgador tiene la convicción moral de que se ha actuado con desviación de poder, aunque el recurrente no haya probado totalmente su existencia. Eso sí, se precisa al menos una prueba indiciaria por el recurrente que alegue la concurrencia de este vicio, no bastando la mera invocación genérica por su parte.

Traemos a colación en este aspecto del control por el fin la sentencia dictada por la Sala de lo Contencioso del Tribunal Superior de Justicia de Andalucía, con sede en Sevilla de 20 de noviembre de 2008, en el recurso n. ${ }^{\circ}$ 1864/1997. Antes de entrar en el comentario de esta sentencia hemos de aclarar que lo tardío de su fecha obedece a que, realmente, la primera sentencia dictada en este recurso, estimatoria del mismo por entender que se había producido la caducidad del procedimiento de declaración de BIC, dictada el 23 de febrero de 2005, fue recurrida por la comunidad autónoma andaluza y, el Tribunal Supremo, estimando el recurso de casación, anuló la sentencia, ordenando a la Sala del Tribunal Superior de Justicia de Andalucía, sede de Sevilla, que dictara nueva sentencia, descartando la existencia de caducidad (el procedimiento no había caducado), y resolviendo sobre el resto de las infracciones invocadas. Volveremos pues sobre esta sentencia dada la variedad de cuestiones abordadas en la misma.

La actora, la Fundación Casa Ducal de Medinaceli, impugnaba la orden de la Consejería de Cultura de la Junta de Andalucía, por la que se acordó inscribir con carácter específico, en el Catálogo General del Patrimonio Histórico Andaluz, con la categoría de monumento, el inmueble denominado casa de Pilatos, en Sevilla.

Entre los distintos vicios que, según la demandante, concurrían en la actuación administrativa impugnada, nos interesa destacar la respuesta que la sala da a la alegación de la actora de que había desviación de poder toda vez que la finalidad perseguida por la Administración andaluza no era propiamente la de proteger el patrimonio histórico, sino que, apartándose del fin legitimador del ejercicio de la potestad, lo realmente pretendido por la $\mathrm{Ad}$ ministración andaluza era vincular el archivo de la casa ducal de Medinaceli como bien mueble, al inmueble denominado casa de Pilatos, pero no a efectos de su protección sino para evitar que éstos (los archivos documentales) salieran fuera de la comunidad autónoma andaluza. 
La sentencia, que finalmente acaba estimando el recurso y anulando la resolución recurrida, descarta sin embargo el fraude de ley y la desviación procesal que alegaba el recurrente, y lo hace señalando en su fundamento jurídico quinto lo siguiente:

"La Comunidad Autónoma Andaluza ostenta competencias sobre el patrimonio histórico. El intento de proteger determinados bienes inmuebles y muebles, que realiza en el procedimiento recurrido, no se puede considerar un uso de potestades administrativas para fines distintos de los perseguidos por el ordenamiento jurídico, en que, según el artículo 70.2 LCA, consiste la desviación de poder denunciada. Se trata de una actividad destinada a proteger bienes que, aparentemente podrian formar parte del patrimonio histórico, lo cual es el uso de la potestad ordenado al fin previsto por el ordenamiento jurídico".

Por último, consideramos igualmente relevante, tanto en lo que se refiere al control judicial por el fin como por los hechos determinantes, la sentencia de 21 de febrero de 2006, del Tribunal Superior de Justicia de Andalucía, sede en Sevilla, recaída en el recurso n. ${ }^{1874 / 2003}$, Sección Primera. En dicho recurso, la sala desestima la demanda interpuesta contra el Decreto de la Junta de Andalucía n. ${ }^{\circ}$ 195/2.003 de 1 de julio por el que se amplía el bien cultural denominado zona arqueológica de Medinat al-Zahra (BOJA, 21 de agosto de 2003).

En ella, como decimos, pueden apreciarse ambas técnicas de control, ya que frente a la alegación digamos "conjunta" del recurrente de que la ampliación de la zona arqueológica de Medinat al-Zahra a más de 1.485 ha carece de motivación al no acreditarse que existan y hayan sido comprobados otros restos arqueológicos que los ya conocidos y así calificados en 1996, para ser considerada, conforme a la ley estatal 16/85 y la andaluza 1/1991 de patrimonio histórico, zona arqueológica, y que a su juicio, el fin perseguido era otro, la sala da una doble respuesta empleando ambas técnicas de control.

Por lo que se refiere al control por los hechos determinantes, la sala considera que, en el expediente administrativo, los técnicos "justifican la ampliación de la delimitación del BIC Medinat alZahra (Córdoba) en un hecho objetivo, que las continuas excavaciones verificaron, que el perimetro, protegido hasta entonces (octubre 2001) a través de las distintas declaraciones y del plan especial de protección del Ayuntamiento de Córdoba, resultaban insuficientes, ya que los limites del sistema urbano califal no estaban integramente incluidos en los expedientes de protección, por lo que propusieron incluir cuatro áreas definidas en el Anexo al Decreto para proteger el conjunto y su inserción en el paisaje (...) Es decir, existe suficiente motivación en el Decreto impugnado por remisión a los Informes obrantes en el expediente y al preceptivo acuerdo de la Comisión Provincial de Patrimonio Histórico, de los que se deduce la finalidad perseguida por el Decreto, de protección de todo el conjunto para enlazar los dos núcleos históricos entre las Almunias y Medinat al-Zahra y evitar la destrucción total

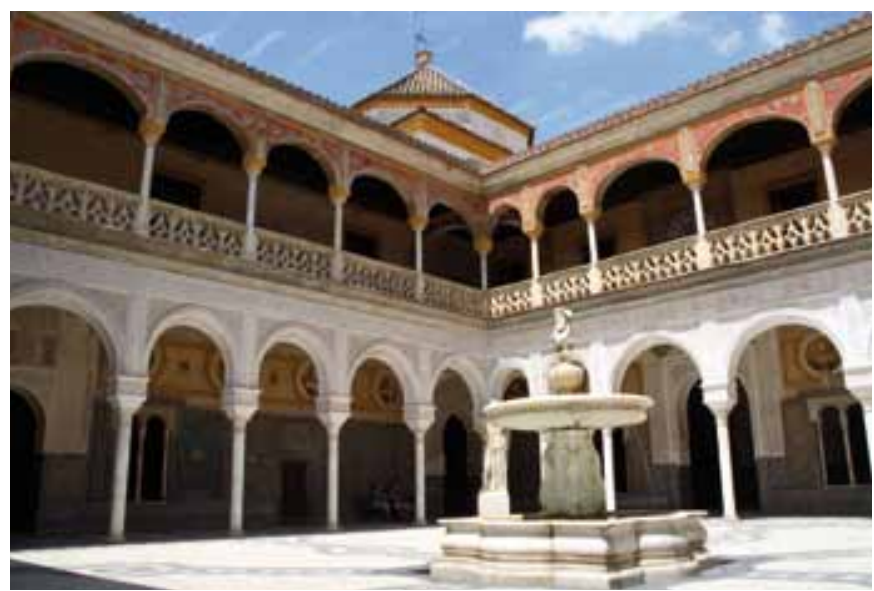

La casa ducal de Medinaceli alegó ante los tribunales que se había producido desviación de poder por parte de la Administración por pretender vincular el archivo de la casa ducal al inmueble casa de Pilatos (Sevilla). Foto: Frédérique Harmsze

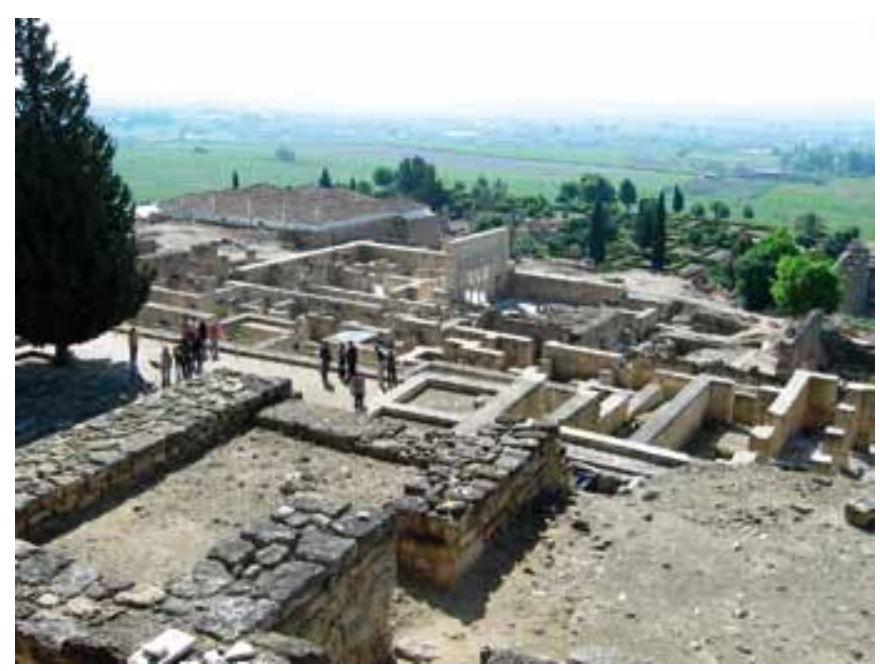

Los tribunales consideraron que en el expendiente administrativo los técnicos justificaban la ampliación de delimitación del BIC Medinat al-Zahra (Córdoba) basándose en hechos objetivos. Foto: Jeremy Vianna

\section{Los informes resultan esenciales para} acreditar la existencia de motivación o fundamentación de la decisión administrativa; deben formar parte imprescindible del procedimiento administrativo tramitado al efecto (...) son esenciales a la hora del control judicial de la concurrencia de los hechos determinantes

de los caminos califales y el cerco de las construcciones ilegales a ambos núcleos" (sic).

En cuanto a la denuncia de desviación de poder y supuesta arbitrariedad en el ejercicio de la potestad discrecional, la sala sentenciadora señala: "...circunstancias que desde luego no concurren en 


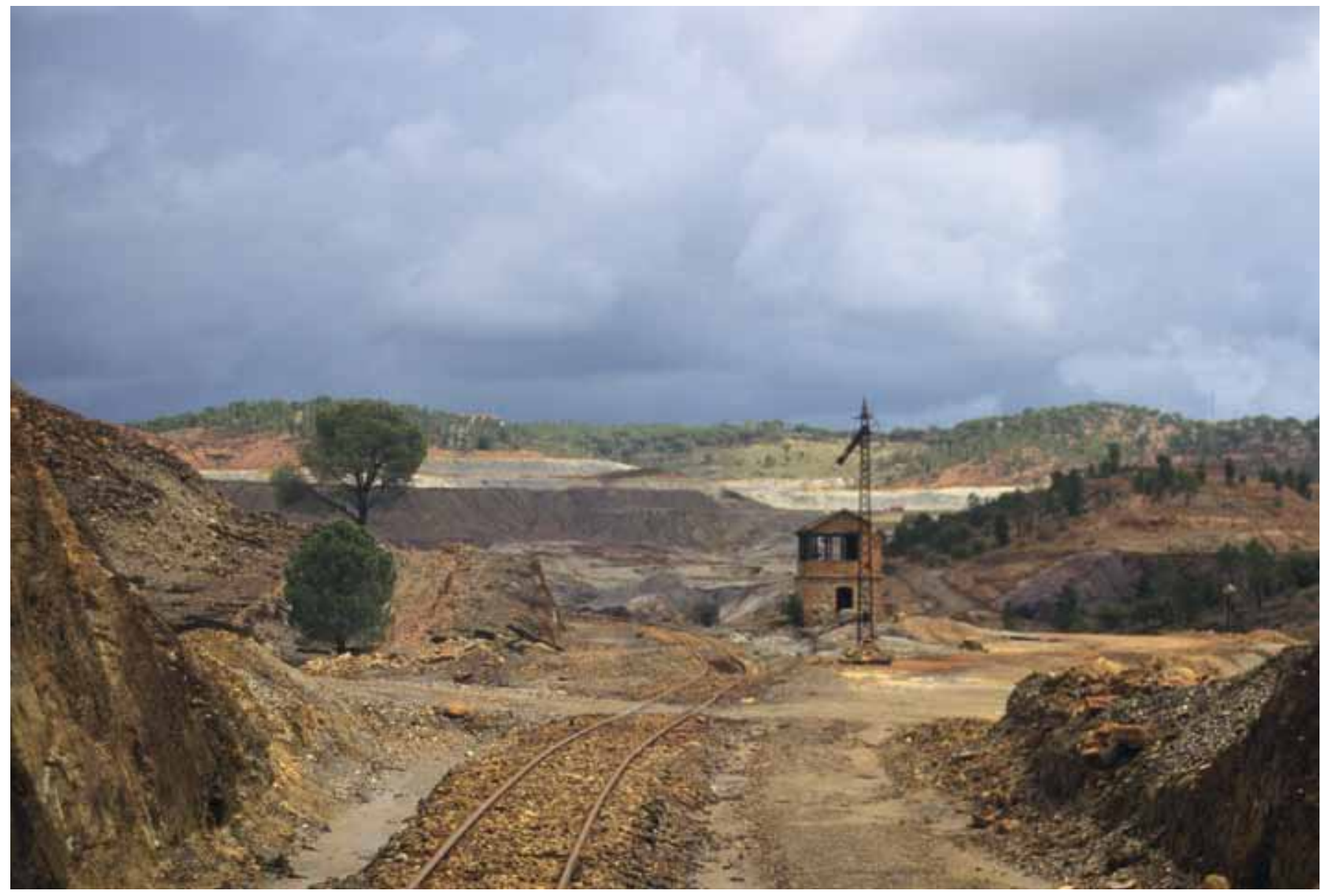

La anulación del decreto por el que se declara BIC la zona minera de Riotinto-Nerva se basa en que no se había producido una notificación personal a los titulares de los bienes afectados. Foto: Fondo Gráfico IAPH (Isabel Dugo Cobacho)

el supuesto que enjuiciamos, porque una noticia periodistica sobre una polémica entre dos políticos de distinto partido no acreditan la desviación de poder denunciada, al ser una mera afirmación subjetiva del autor de la noticia y frente a los proyectos e informes técnicos que justifican la ampliación, no pueden prevalecer las afirmaciones subjetivas del actor que cree suficiente los instrumentos anteriores, porque el propio Ayuntamiento de Córdoba autor del Plan Especial de Protección, considera éste insuficiente para la debida conservación del Conjunto histórico".

- El control judicial del acto a través del control de los elementos reglados del acto

Llegamos ya a lo que constituye la última fórmula o técnica de control judicial de los actos dictados en ejercicio de potestades en el ámbito de la denominada discrecionalidad técnica, es decir, el control a través de los elementos reglados.

Con esta técnica de control, el tribunal analiza eventuales vicios o defectos del acto como tal y del procedimiento empleado para su dictado.

Entre los eventuales vicios de nulidad o anulabilidad que pueden afectar a los denominados elementos reglados, merecen destacarse por su reiteración, en tanto son alegados en los recursos, los que afectan a:
- La competencia: la pretendida incompetencia, que se hace valer al amparo del artículo 62 1.b, viene a poner en cuestión la tradicional polémica de si estamos ante competencias concurrentes, compartidas o exclusivas. Es decir, plantean si la competencia corresponde a la Administración del Estado o a la de la comunidad autónoma.

Sin ánimo de ser exhaustivos, dado el ámbito de nuestro análisis, sí queremos citar la sentencia del Tribunal Supremo dictada en el recurso de casación 294/2006, interpuesto por la comunidad autónoma andaluza contra sentencia de la Sala del TSJA sede en Sevilla que, estimando el recurso interpuesto por RENFE, anulaba el Decreto 73/2003 de la Junta de Andalucía que declaró BIC, con la categoría de monumento, el muelle o cargadero mineral de la Compañía Río Tinto, en Huelva. El recurso se estimaba sobre la base de que dado que el bien se encontraba adscrito a un servicio público estatal, la competencia para la declaración correspondia a la Administración estatal. Por el contrario, para el TS, tal adscripción a un servicio público estatal no es obstáculo para que, legítimamente, en ejercicio de sus competencias en materia de protección del patrimonio histórico andaluz, la comunidad autónoma incluya el bien en cuestión en el entorno del BIC.

- Caducidad: otro vicio muy recurrente es el de la caducidad del procedimiento de declaración de BIC. 
En esta materia es muy variada la doctrina jurisprudencial, hasta el punto de que el propio Tribunal Supremo ha oscilado notablemente en sus pronunciamientos.

Entre las muchas sentencias dictadas sobre el tema de la caducidad del procedimiento de declaración de BIC, podemos citar la sentencia del Tribunal Supremo de 27 de mayo de 1999, recurso 386/1997, en el caso de los toros de Osborne, donde se estimó la caducidad y se anuló la declaración; o la del caso de los archivos de la casa ducal de Medinaceli y la casa de Pilatos, sentencia del Tribunal Supremo de 2 de julio de 2008, recurso de casación $4810 / 2005$.

- Trámites esenciales: en este punto los principales vicios que se invocan vienen referidos al artículo 62 de la Ley 30/1992, como si implicaran prescindir absolutamente del procedimiento, y vienen a vincular la ausencia de determinados trámites (alegaciones, audiencia...) con la producción efectiva de indefensión. Determinarian pues la nulidad de la actuación administrativa.

- Notificaciones: también resulta éste un vicio muy invocado, el de la defectuosa notificación, vinculada, al igual que el vicio anterior, a la producción efectiva de indefensión.

Es relevante para el análisis de este vicio, la sentencia del Tribunal Supremo de 23 de marzo de 2011, dictada en el recurso de casación 4264/2009, desestimatoria de la casación interpuesta por la comunidad autónoma andaluza contra la sentencia dictada por el TSJA, sede de Sevilla, por la que se anula el decreto por el que se declara $\mathrm{BIC}$, con la categoría de sitio histórico, la zona minera de Riotinto-Nerva, ubicada en los términos municipales de Minas de Riotinto, Nerva y El Campillo. El motivo de la anulación es que a juicio de la sala, la interpretación conjunta de los preceptos aplicables, imponía, además de un trámite de información pública y la audiencia a los ayuntamientos afectados, efectivamente verificados, una "notificación personal a los interesados, por cuanto que la declaración que se efectuó llevaba consigo determinados efectos que afectaban los derechos de la titular de los bienes, que en consecuencia, debía ser oída".

\section{CONCLUSIONES}

El presente trabajo ha pretendido abordar la problemática que suscita el control judicial de la actuación de la Administración Pública cuando ésta ejerce potestades de naturaleza discrecional pero eminentemente técnicas, como es el caso de las ejercitadas en el ámbito de la protección del patrimonio histórico.

Nos hemos centrado en la problemática procesal con objeto de conseguir con ello detectar los problemas advertidos en la tramitación de estos procedimientos, y con la intención de poder con ello incidir, preventivamente, de cara a futuras actuaciones en la materia.
Nuestras consideraciones sobre el tema nos llevan a las siguientes conclusiones:

- Necesidad de control: como en el resto de la actividad administrativa, el control judicial es la garantía en un Estado de Derecho de que la Administración actúa sometida al principio de legalidad y ejerce las potestades que el ordenamiento le confiere en aras de la salvaguarda de los intereses generales.

- Control limitado: la limitación del control, que en modo alguno puede ser interpretada como "exención de control", viene dada por la especial naturaleza discrecional técnica de las potestades que se ejercitan. Discrecionalidad no es arbitrariedad. En su enjuiciamiento de la actuación administrativa: 1. Los tribunales no pueden sustituir a la Administración en su juicio técnico, sólo anularlo; 2. Los tribunales cuando enjuician la actuación administrativa y por lo que se refiere al contenido técnico de la misma han de limitarse a constatar su existencia y racionalidad, sin perjuicio del empleo de las distintas técnicas de control que hemos expuesto.

- Discrecionalidad técnica y base fáctica: El juicio técnico precisa de unos datos objetivos que permitan deducir la aptitud o ineptitud del mismo; La existencia de ese mínimo fáctico es controlable judicialmente.

Aunque excede al presente estudio, no queremos cerrar el análisis de la problemática procesal que suscitan los procedimientos judiciales de control de la actuación administrativa en materia de protección del patrimonio histórico, sin referirnos a un problema adicional derivado del hecho esencial de que las administraciones autonómicas en el ejercicio de sus competencias en esta materia, aplican, fundamentalmente, si no exclusivamente en muchos casos, Derecho autonómico.

Este dato que, en principio, no puede ser interpretado como negativo, evidentemente, impide, sin embargo, en muchos casos, el acceso al recurso de casación ante el Tribunal Supremo, lo que procesalmente supone una limitación importante, ya que priva de la posibilidad de revisión de sentencias de los tribunales superiores de justicia, imposibilitando la rectificación de los criterios de éstos. En efecto, el Tribunal Supremo, como declara la Ley de la jurisdicción contencioso-administrativa, no es el competente para conocer de la infracción del Derecho autonómico, ya que el Supremo intérprete de éste es el Tribunal Superior de Justicia de la comunidad autónoma en cuestión.

\section{Bibliografía}

BARRERO RODRÍGUEZ, C. (1990) La ordenación jurídica del Patrimonio Histórico. Madrid: Civitas-Instituto García Oviedo, 1990

BARRERO RODRÍGUEZ, C. (1996) Discrecionalidad administrativa y Patrimonio Histórico. En HINOJOSA, E.; GONZALEZ-DELEITO, N. (coord.) Discrecionalidad Administrativa y control Judicial. I Jornadas de Estudio del Gabinete Jurídico de la Junta de Andalucía. Madrid: Civitas; Junta de Andalucía,1996 